\title{
Performance ANalysis ANd Comparison OF IMPROVED DSR WITH DSR, AODV AND DSDV Routing Protocol IN MOBILITY AND Non- MOBILITY SCENARIOS
}

\author{
Paresh Acharekar, Dr. Saurabh Mehta and Prof.Shraddha panbude \\ Department of Electronics and Telecommunication, Vidyalankar institute of Technology, \\ Mumbai India.
}

\begin{abstract}
Mobile Ad-hoc networks are categorized by multi-hop wireless connectivity and numbers of nodes are connecting each other through wireless network. It includes several routing protocols specifically designed for ad-hoc routing. The most widely used ad hoc routing protocols are Ad-hoc On Demand Distance Vector $(A O D V)$, Destination Sequence Distance Vector (DSDV), and Dynamic Source Routing (DSR). In this paper, we present an analysis of DSR protocol and propose our algorithm to improve the performance of DSR protocol by using small delay applied on last route ACK path when an original route fails in Mobile Ad Hoc networks. Past researchers the MANET have focused on simulation study by varying network parameters, such as network size, number of nodes. The simulation results shows that the M-DSR protocol having some excellent performance Metrics then other protocols. We have taken different performance parameters over the comparison of Modified -DSR with other three protocols in mobility as well as Nonmobility scenario up to 300 nodes in MANETs using NS2 simulator. To achieve this goal DSR is modified by using modified algorithm technique in order to load balancing, to avoid congestion and lower packet delivery.
\end{abstract}

1. Our area of interest for the paper is the improvement of performance of DSR routing protocol by changing in algorithm and this Improved DSR protocol should compare with remaining protocols taken in this research paper.

2. In this paper we made changesin traditional DSR protocol and generation of new improved DSR the different performance parameters and compare with AODV/DSR/DSDV protocols in mobility and non- mobility scenarios nodes up to 300.

3. We can plot the graphs throughput, End to end Delay, Packet delivery Ratio, Dropping Ratio, and average energy consumption on Mobility and Non-Mobility scenario by using Network Simulator version 2.34 for Modified DSR protocols. M-DSR, DSDV perform well when Mobility is low.

\section{KEYWORDS}

Ad Hoc Networks, Mobility Models, AODV, DSDV, EX-DSR and NS2.34

\section{INTRODUCTION}

A name of MANET which is a group of nodes and collection of nodes communicate with each other wireless fashion. In MANETs, because the nodes move arbitrarily these results in route changes with a good chance of packet dropping sometimes fault detection is difficult. Several previous studies indicate that some of the route formation and discovery techniques we can proportionate and optimized the traditional protocols which has actually hurt the performance in many situations and make Improved DSR. [3].

DOI : $10.5121 /$ ijp2p.2016.7401 


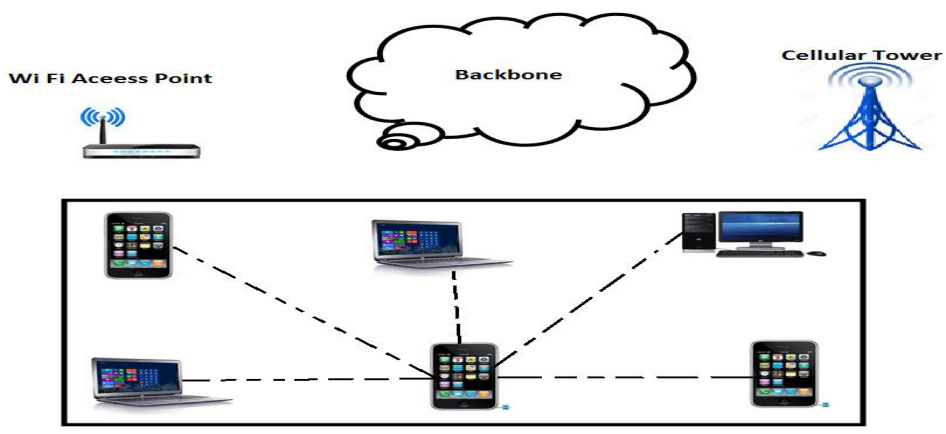

Fig1.1 Mobile Ad-hoc Network [25]

We propose three simple and intuitive changes to the routing protocol: (a) limitation of RREQ to destination with the number of route requests from sources, (b) sorting the fresh routes with RREP (c) limiting the number of routes 0kept per destination to one. Illustrate the relative significance changes the algorithm for DSR protocol. In this paper, we present a modified DSR protocol for reverse request ACK received to source and delay has applied for $2^{\text {nd }}$ last node which is transfer data packets and dropping of routes hence decreases end to end delay, increase the data packet delivery ratio [12].

\section{Routing Protocols Of MANet}

Routing protocols for wired infrastructure neither need to handle mobility of nodes within the system nor have these protocols to be designed with reference of protocols. Most importantly, the routing protocols both wireline or wireless infrastructure are assumed to execute on trusted entities, namely the routers. But these characteristics change completely when Mobile Ad-Hoc Networks (MANETs) are considered as there are no special routers in MANETs. Hence, each node must perform routing functions in order to forward a packet to the destination. Therefore, routing protocols need to be specifically designed for MANETs [14].

\section{Classification of MANets Routing Protocol}

Based on the instance at which the routes are set up, routing protocols for MANETs can mainly be classified into the three categories [19] illustrated in Figure 2.

\section{- Table-Driven (Or Proactive) Routing Protocols}

\section{i. DESTINATION SEQUENCED DISTANCE VECTOR (DSDV)}

This algorithm uses routing table like Distance vector every routing table tagged with the sequence number, generated by destination. Each mobile station advertises its own routing table to its current neighbors [13]. DSDV is one of the early algorithms available and the main advantage of every entry should mark in sequence number and every node maintains a list of all destinations.

\section{- Reactive Routing (On-Demand) Protocol}

\section{ii. AD Hoc ON DEMAND Distance VeCTOR (AODV)}

In this Route Request (RREQ) and Route Reply (RREP) in route discovery process. When the packet transverse source to destination then destination node received the RREQ request and to 
set reverse path. When the RREQ reaches a mobile node, which knows a route to the destination or the destination itself, the mobile node responds to the RREP request sent from destination node to intermediate nodes. The Route Reply travels along the reverse path setup when Route Request is forwarded [7].

\section{iii. DYNAMIC SOURCE ROUTING (DSR):}

In DSR, the RREQ packet contains all the information of destination route which is route request packet as it is propagated through the network. When RREQ request received in destination. This means that the source may receive several RREP messages.DSR should select optimize path which maintenance process to speed up the route. The main difference between DSR and AODV:in DSR it is stored in the source while in AODV. In discovery phase of both is based on flooding \&regardless of their potential in actually set up the network load [10]

\section{Project Process Structure}

Please find the above flow chart of my M.E research project process diagram which is showing of performance of routing protocols. We have taken some stuff which is helping much to enhance work, taken into account choosing the data should be done carefully in order to obtain correct information. This data will be analyzed and criticized as well. The below flow chart fig 2.2 is process structure of research paper and will carry out the main steps for this project to achieve the objectives to understand the project. In this work we have developed improved DSR and comparatively study with rest of three protocols which have taken using NS2 simulator under Linux OS.

\section{FLOW CHART}

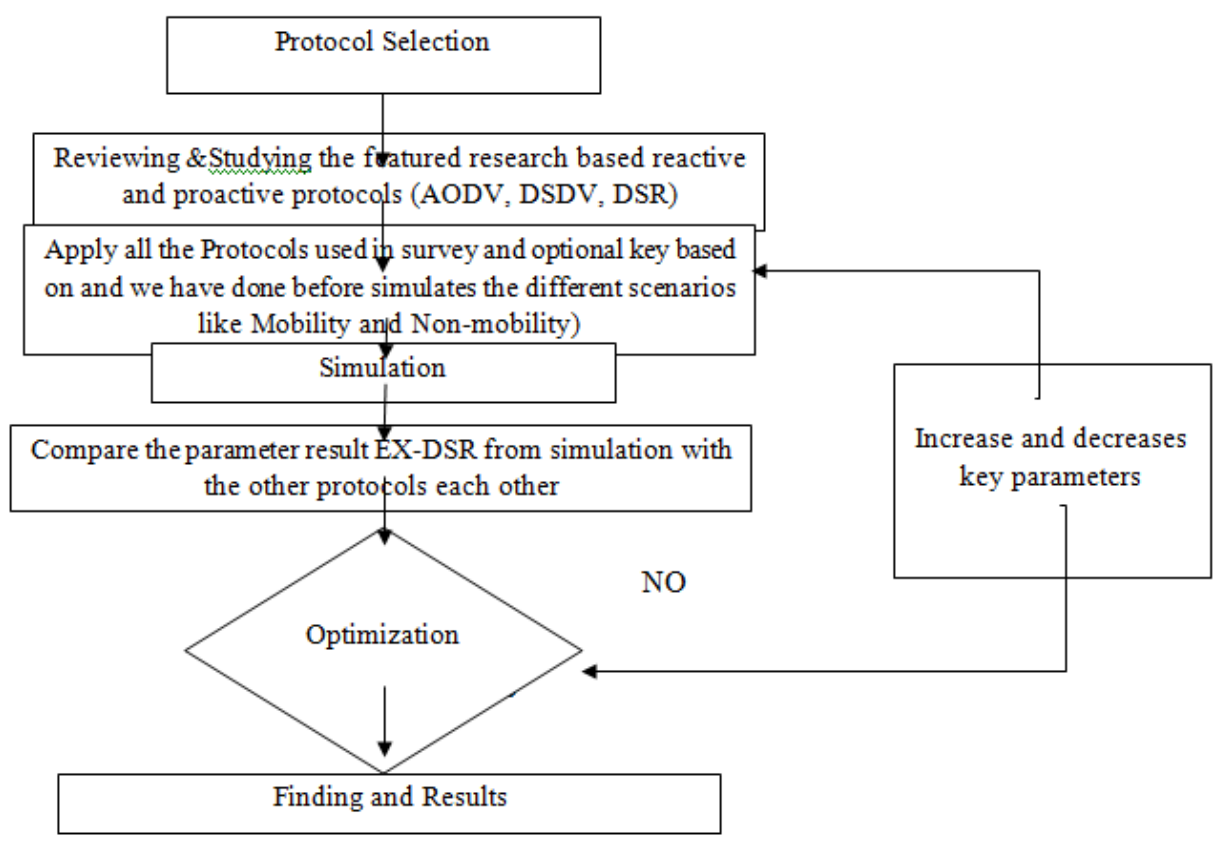

Fig:2.2 Process structure of Flow chart 


\section{RElated WORK}

Please follow the below table for the performance of Routing Protocols and previous researcher work. I have added extension of this work with my research and implementation of this ides in my research paper.

\begin{tabular}{|c|c|c|c|c|}
\hline $\begin{array}{l}\text { Sr } \\
\text { No }\end{array}$ & References & Parameter & $\begin{array}{c}\text { Previous Work } \\
\text { analysis }\end{array}$ & Implementation of project \\
\hline 1 & $\begin{array}{l}\text { Samayveer et al } \\
{[13], \text { Ashish et al }} \\
\text {.[10] }\end{array}$ & Work & $\begin{array}{l}\text { AODV and DSR used } \\
\text { in On demand route } \\
\text { discovery } \\
\text { phenomenon's did use } \\
\text { for source routing and } \\
\text { route cache. }\end{array}$ & $\begin{array}{l}\text { working on route discovery } \\
\text { and route maintenance in } \\
\text { Improved DSR }\end{array}$ \\
\hline 2 & $\begin{array}{c}\text { Parul s et } \\
\text { al.(18),Sandeep } \\
\text { Gautam et al. [1], }\end{array}$ & $\begin{array}{l}\text { Protocols } \\
\text { used }\end{array}$ & $\begin{array}{c}\text { Comparison of } \\
\text { DSR,DSDV,AODV } \\
\text { with performance } \\
\text { metrics }\end{array}$ & $\begin{array}{c}\text { We have improved the delay } \\
\text { and dropping ration in Ext- } \\
\text { DSR }\end{array}$ \\
\hline 3 & $\begin{array}{l}\text { M. Q. Rafiq et al. } \\
\text { (10) and Dipankar } \\
\text { S et al. (22) }\end{array}$ & $\begin{array}{l}\text { Performance } \\
\text { criteria }\end{array}$ & $\begin{array}{l}\text { As per simulation } \\
\text { work, AODV protocol } \\
\text { shows better } \\
\text { performance as } \\
\text { compared with others } \\
\text { in higher number of } \\
\text { nodes (up to 200) }\end{array}$ & $\begin{array}{l}\text { As per simulation work DSR } \\
\text { perform low as high number } \\
\text { of nodes so we will improve } \\
\text { the performance of modified } \\
\text { DSR (similar to AODV) } \\
\text { with largest no of nodes (up } \\
\text { to } 300 \text { )using Routing } \\
\text { Algorithm for Ex-DSR }\end{array}$ \\
\hline \multirow[b]{2}{*}{4} & Preeti G et al. [19] & \multirow[b]{2}{*}{$\begin{array}{l}\text { Packet } \\
\text { delivery } \\
\text { Ratio }\end{array}$} & \multirow{2}{*}{$\begin{array}{l}\text { As per graphs the DSR } \\
\text { PDR performance } \\
\text { decline drastically (up } \\
\text { to } 100 \text { nodes) when the } \\
\text { increased no of node }\end{array}$} & \multirow{2}{*}{$\begin{array}{c}\text { We will improve PDF } \\
\text { performance of modified } \\
\text { DSR when increasing no of } \\
\text { nodes ( after 100) using the } \\
\text { modified algorithm }\end{array}$} \\
\hline & Liliana E et al.[4] & & & \\
\hline 5 & Gulati et al. [17] & Nodes & $\begin{array}{l}\text { In this paper author } \\
\text { worked on nodes in } \\
\text { one scenario and An } \\
\text { detailed simulation of } \\
\text { DSDV, AODV, DSR } \\
\text { with } 200 \text { mobile nodes }\end{array}$ & $\begin{array}{l}\text { AODV show good } \\
\text { performance in a network } \\
\text { with low mobility whereas } \\
\text { AODV We have used up to } \\
300 \text { nodes so that an } \\
\text { Improved DSR improve the } \\
\text { throughput and packet } \\
\text { dropped parameters }\end{array}$ \\
\hline 6 & $\begin{array}{c}\text { Sabina Barakoviet } \\
\text { al. [5] }\end{array}$ & $\begin{array}{l}\text { Performance } \\
\text { criteria }\end{array}$ & $\begin{array}{l}\text { We carried out the } \\
\text { simulation analysis of } \\
\text { AODV and DSR. } \\
\text { Their simulation has a } \\
\text { model of } 50 \text { and } 100 \text { at } \\
\text { varying number of } \\
\text { nodes. } \\
\text { The throughput and } \\
\text { the average end-to end } \\
\text { delay are used as the } \\
\text { evaluation metrics for } \\
\text { the simulations. }\end{array}$ & $\begin{array}{l}\text { Their main finding is that } \\
\text { source routing is much more } \\
\text { efficient than the distance- } \\
\text { vector-based protocols, like } \\
\text { AODVso that we have to use } \\
\text { EX-DSR protocol Algorithm } \\
\text { to improve maximum } \\
\text { performance parameter Ratio } \\
\text { with higher number of } \\
\text { nodes. }\end{array}$ \\
\hline 7 & $\begin{array}{l}\text { P.Manickam et al. } \\
{[12]}\end{array}$ & $\begin{array}{l}\text { Protocols } \\
\text { used }\end{array}$ & $\begin{array}{l}\text { Performance } \\
\text { comparison of two } \\
\text { prominent on-demand } \\
\text { reactive routing } \\
\text { protocols (DSR and }\end{array}$ & $\begin{array}{l}\text { Ex-DSR preferable for } \\
\text { comparatively average } \\
\text { amount of mobility and low } \\
\text { traffic as per AODV } \\
\text { protocol. }\end{array}$ \\
\hline
\end{tabular}


International Journal of Peer to Peer Networks (IJP2P) Vol.7, No.1/2/3/4, November 2016

\begin{tabular}{|c|c|c|c|c|}
\hline & & & $\begin{array}{l}\text { AODV) shown in } \\
\text { previous thesis and } \\
\text { one proactive routing } \\
\text { protocol (DSDV) is } \\
\text { presented. }\end{array}$ & \\
\hline 8 & $\begin{array}{c}\text { PrachiguptaE et al } \\
{[20]}\end{array}$ & $\begin{array}{l}\text { Performance } \\
\text { criteria }\end{array}$ & $\begin{array}{l}\text { Here the Performance } \\
\text { comparison of AODV } \\
\text { and DSR routing } \\
\text { protocols in a } \\
\text { constrained situation is } \\
\text { done in paperThe } \\
\text { authors claim that the } \\
\text { AODV outperforms } \\
\text { DSR in normal } \\
\text { situation but in the } \\
\text { constrained situation } \\
\text { DSR out performs } \\
\text { AODV. }\end{array}$ & $\begin{array}{l}\text { We have used Ex-DSR } \\
\text { routing Algorithm to reach } \\
\text { the AODV performance } \\
\text { parameters. }\end{array}$ \\
\hline 9 & $\begin{array}{c}\text { DrMudassar et al } \\
{[21]}\end{array}$ & $\begin{array}{l}\text { Application } \\
\text { Metrics }\end{array}$ & $\begin{array}{c}\text { For application } \\
\text { oriented metrics such } \\
\text { as delay and } \\
\text { throughput, DSR } \\
\text { outperforms of AODV } \\
\text { when the numbers of } \\
\text { nodes are smaller } \\
\text { thenDSR is good one } \\
\text { mentioned in this } \\
\text { paper }\end{array}$ & $\begin{array}{l}\text { We have used Ex-DSR } \\
\text { routing Algorithm to reach } \\
\text { good performance of all } \\
\text { performance parameter. }\end{array}$ \\
\hline 10 & $\begin{array}{c}\text { Nitin Tyagi et al } \\
{[16]}\end{array}$ & $\begin{array}{l}\text { congestion } \\
\text { and } \\
\text { performance } \\
\text { parameter }\end{array}$ & $\begin{array}{l}\text { Worked on upto } 50 \\
\text { nodes with CBR traffic } \\
\text { in MANET but higher } \\
\text { nodes congestion } \\
\text { might happened in this } \\
\text { scenario. }\end{array}$ & $\begin{array}{l}\text { We have proposed the } \\
\text { Improved DSR in both } \\
\text { mobile nodes as well as } \\
\text { constant nodes upto } 300 \text { and } \\
\text { we get some positive results } \\
\text { in performance parameters. }\end{array}$ \\
\hline
\end{tabular}

Table:3.2 Various Research Paper

\subsection{Performance Metrics}

This subsection provides the general terminology of performance metrics that we consider for the simulations throughout our research work presented in this thesis.

\section{- Packet Delivery Ratio :}

Packet Delivery Fraction $=$ received packets/sent packets $* 100$.

- AVERAGE END TO END DELAY :

This has all delays influenced by discovery process and queuing at rebroadcast packets in delay at the MAC, propagation and transfer times of data packets.

\section{- ThroughPUT :}

When the numbers of packets are broadcast then same number of data packets received per unit time in the network during the simulation. 
International Journal of Peer to Peer Networks (IJP2P) Vol.7, No.1/2/3/4, November 2016

\section{- Packet Dropping Ratio :}

Packet Delivery Ratio (PDR) is the ratio between the number of packets transmitted by a source and a number of packets received by a sink (destination).

- Average EnERgy CONSUMPTION:

Average Energy has been consumed when the packet has sent in network.

\subsection{NETWORK SIMULATOR 2}

In this paper, we use NS2 to simulate our proposed model and evaluate the performance of MDSR with DSR.NS2 is an object oriented, open source network simulation tool, which can be used by researchers both the networks. The languages are used in NS2, OTcl and C++. Moreover, NS2 supplies number of models and protocols can help us of NS2 shows in below.We use OTcl script file for simulation, then NS2 interpret the script and output the simulation process and result to an output file. The simulation process and result can be shown by Nam and X graph files. Please find the network simulator output file [9].

\section{Evaluation OF MODIFIEd DSR}

We analysed the performance of the original DSR previous research and the impact of DSR components discussed and with the reference of explanation on intermediate node replies, we modified the DSR code so that when any fresh route form or new request come in the network We also modified the route replies and track of route creation time and ages of routes used.

\section{A. DESCRIPTION OF MOdified Algorithm}

In the original DSR protocol, when source node has no route for destination in its route cache then it generate a route request message for searching route, and then broadcasted to a network till the time to live is expired or the route is found. All the intermediate nodes are without considering no. of hope it may have which will cause congestion at node which will affect the overall performance of DSR protocol so that I have proposed that Improved DSR protocol (EXDSR) which has improvement done in the route reply (RREP) method Due to number of nodes sends the RREP created the congestion and caused the collisions in network in normal DSR.

Each data packet sent then carries in its header the complete the request to nodes. We have included the delay on reverse ACK path from the source (we just introduce a delay on last node when destination sends a RREP).In dynamic source routing. Our proposal is to modify the basic DSR to reduce the redundant RREPs. The below figure showing the basic architecture of Ex-DSR protocol [21].

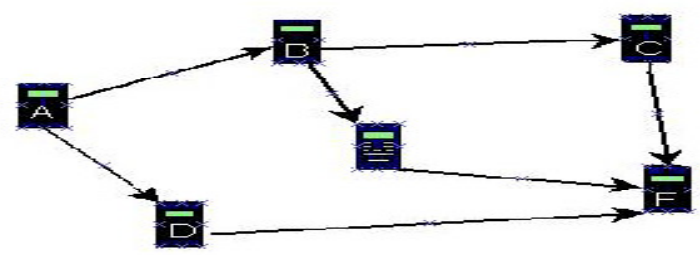

Figure: 4.1 EX-DSR working scenario [18] 
Suppose node A want to communicate with node F, then it may be possible that node A have no straight link with node $\mathrm{F}$, but it have link with node $\mathrm{B}$ who has link with node $\mathrm{C}$ and $\mathrm{E}$, and $\mathrm{E}$ \& $\mathrm{C}$ is further linked with $\mathrm{F}$. So node A will use intermediate node to communicate with node $\mathrm{F}$. The node in mobile ad hoc can be a mobile, notebook, and computer. All of these nearest node have the route to destination node in its route cache like node A has the route "BCF" and "BEF" and neighbour D is direct link to F. All the intermediate nodes which will cause congestion at node B which will affect the overall performance of DSR protocol. To solve such type of problem DSR should prevent route reply storm and the idea is given in DSR RFC. In our work we just introduce a delay on last node when destination sends a RREP. The original DSR keeps multiple routes to a destination and minimum hop count routes we modified the route cache such that it maintains routes [22]. The below figure 4.1 flow chart evaluated the difference of traditional DSR and modified DSR working mechanism.

\section{TRADITIONAL DSR}

Please find the below DSR header format which includes the below parameters.

- The Small fixed-sized, sequence of 0 carried of 4-octet portion or DSR options carrying optional information. For IPv4, the DSR header carried out the IP header in the packet followed by traditional UDP.

- When the header allows the DSR option header present in packet, then multiple number 4 octets are present in actual length of DSR option header which has total combined length present.

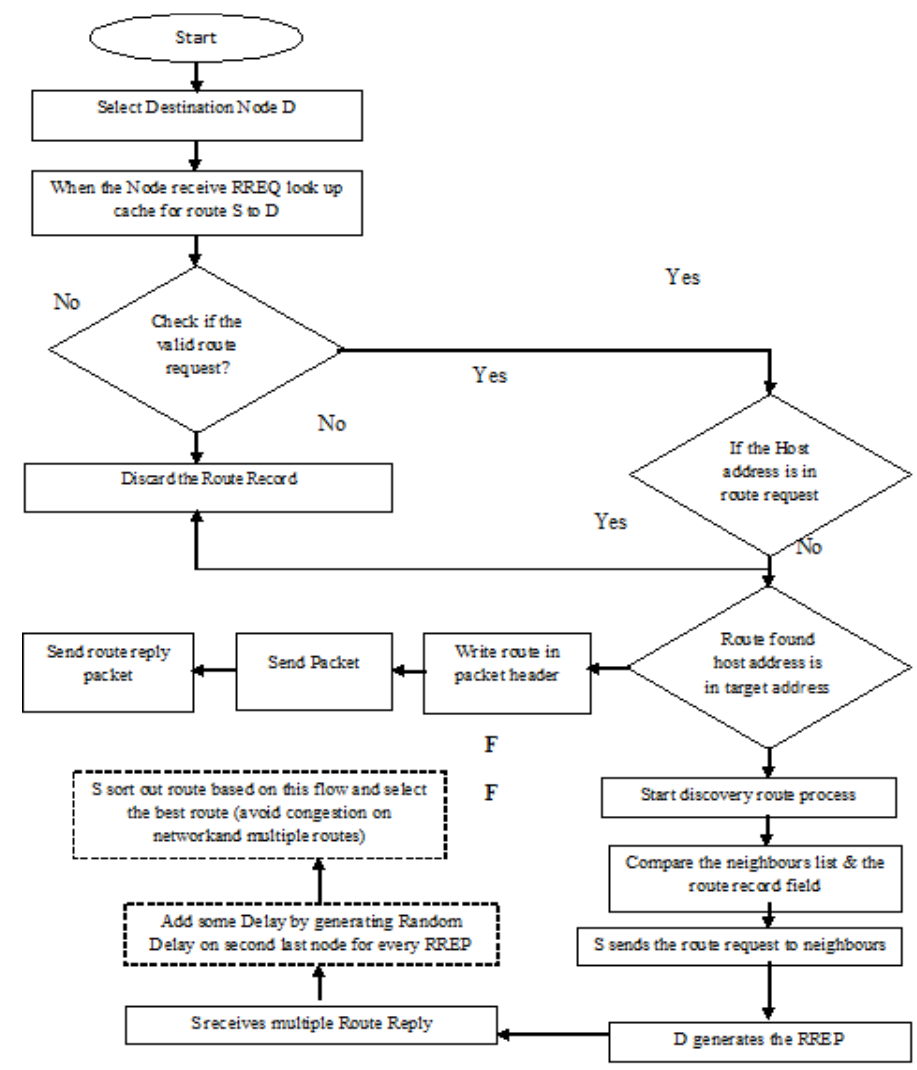

Fig 4.1Packet Formats of Modified DSR 


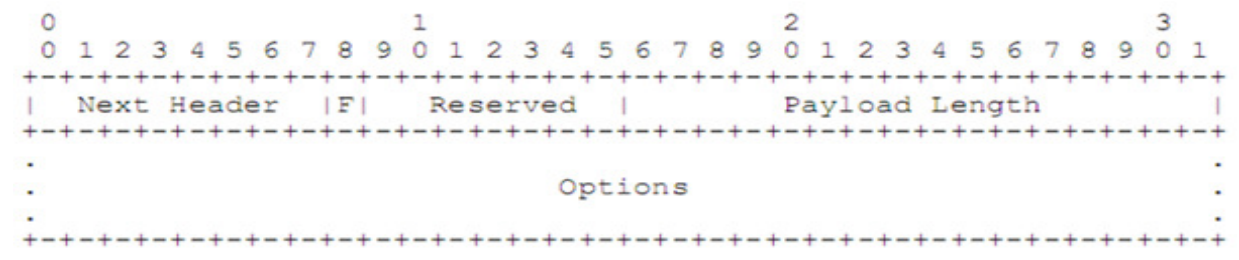

Fig : 4.2 Fixed Portion of DSR Options Header

\begin{tabular}{|c|c|c|c|c|c|}
\hline $\begin{array}{c}\text { Source Node } \\
\text { Address }\end{array}$ & $\begin{array}{c}\text { Intermediate } \\
\text { Node } \\
\text { Address }\end{array}$ & $\begin{array}{c}\text { Intermediate } \\
\text { Node } \\
\text { Address }\end{array}$ & $\begin{array}{c}\text { Intermediate } \\
\text { Node } \\
\text { Address }\end{array}$ & $\begin{array}{c}\text { Destinatin } \\
\text { Node } \\
\text { Address }\end{array}$ & DATA \\
\hline
\end{tabular}

Fig: 4.3. Data Packet Format of DSR protocol

\section{B. MODIFIED DSR}

In technicality, information from the transmission links, such as packet header, should pass all the route information to source node towards the intermediate nodes of paths in routing of protocol. Each wireless node can communicate with any node within range, which depends on capacity at the receiver node. We modified the route reply packet format addition of random delay on last node with packet format is worst value of signal strength along with delay parameter route from destination to source.First we modify the protocol's internal data structure to add additional field for storing the small delay value during the route Reply process. The changes have been made particularly to the RREQ, RREP and route cache. The Modified DSR has good throughput and PDR less delay compared with Conventional DSR.

\begin{tabular}{|c|c|c|}
\hline $\begin{array}{c}\text { Next Header } \\
\text { (8 Bits) }\end{array}$ & \multicolumn{2}{|c|}{$\begin{array}{c}\text { Reserved } \\
\text { (8 bits) }\end{array}$} \\
\hline Options & Data & $\begin{array}{c}\text { Raydom delay with } \\
\text { Signal strength (8 bits) }\end{array}$ \\
\hline
\end{tabular}

Fig: 4.4 Modified Route Reply packet format of DSR

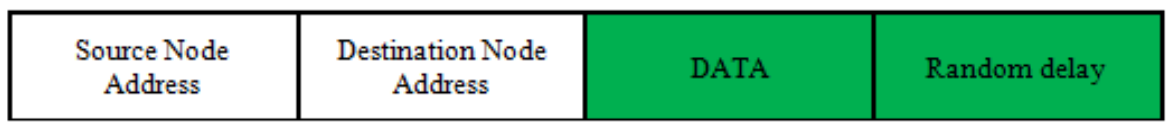

Fig :4.5 Data Packet Format of Modified DSR protocol

\section{PSEUdo Code}

1. Get route for packet from source to destination

2. I* make the route request packet */

3. $/ *$ make the route request packet $* /$

4. \# end if $/ *$ NEW_SALVAGE_LOGIC *

5. Send route code

6. Send packet after accepting route reply

7. Code to send route request

8. Code to return response to the source as request 


\section{Simulation Set UP}

In the simulation Modified DSR use unique optimization method in as per name SRD. We have taken the below parameters for simulation of EX-DSR protocol with find out the average end to end delay, Packet delivery ratio, Throughput and Average Energy Consumption for $50,100,150,200,250$ and 300 nodes. In the simulation, it has been shown that the performance of E-DSR is much better than DSR. The Mobile ad-hoc network consists of up to 300 wireless nodes, moving about over 500 X 500 flat spaces for 200 seconds of simulated time. The constant bit rate (CBR) flows are deployed for data transmission. The RWP model is used in simulation. In order to enable direct, fair comparisons between the DSR, AODV, DSDV and EX-DSR, Each run of the simulator accepts a scenario fileas input that actual movement of every node and set as all the data of packets in sequential manner. The evaluations are based on the simulation of two scenarios. The simulation set up remains same for first part only includes the modified EX-DSR protocol with mobility and non-mobility scenario in MANET (802.11In simulator uses the motion of mobile nodes and non-mobile nodes.In this simulation the traffic sources to be constant bit rate $(\mathrm{CBR})$ source.

\begin{tabular}{|c|c|}
\hline Parameter & Parameter Value \\
\hline Simulator & NS-2.34 \\
\hline Simulation gid size & $500 \mathrm{x} 500$ \\
\hline MAC layer Protocol & MAC 802.11 \\
\hline Channel type & Wireless channel \\
\hline Routing protocols & EX-DSR \\
\hline Mobile nodes & 50.100 .150 .200 .250 .300 \\
\hline Antenna Type & Omnidirectional antenna \\
\hline Propagation Model & Two Ray Ground \\
\hline Packet size & 500 bytes \\
\hline Traffic & CBR (UDP) \\
\hline Simulation time & 200 sec \\
\hline Link Layer & Type LL \\
\hline Mobility Model & Random Way point model \\
\hline Maximum speed & $10 \mathrm{~m} / \mathrm{s}$ \\
\hline
\end{tabular}

5.1Parameter values taken in simulation

\section{Graphs EX-DSR With Three Protocols In Mobility Scenario}

\subsubsection{THROUGHPUT}

From the above figure 6.1.1 it is clear that EX-DSR has very good throughput then the other protocols AODV and DSR. For DSDV protocol, first the throughput decreases and remains constant for some time. However it is not consistent over the period of time.The AODV shows the consistent behaviour over a period of time for different number of nodes.Thus AODV and EX-DSR shows a better performance as compared to other two protocols. 
International Journal of Peer to Peer Networks (IJP2P) Vol.7, No.1/2/3/4, November 2016

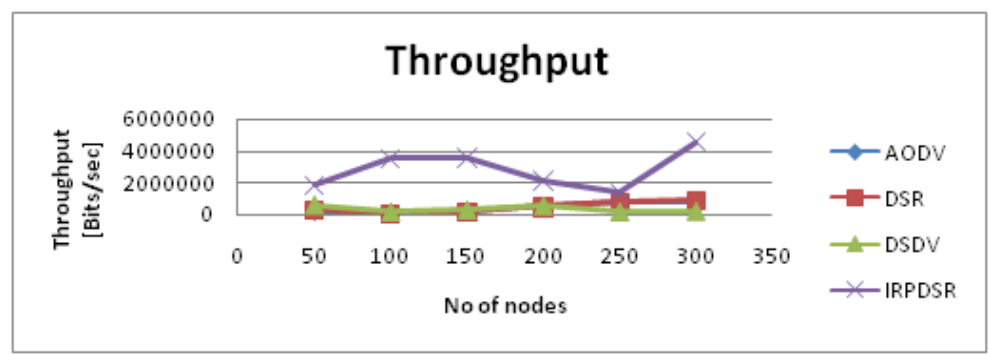

Fig: 6.1.1 Throughput vs Number of Nodes

Table 6.1.1 Readings of Throughput vs No of nodes

\begin{tabular}{|c|c|c|c|c|}
\hline $\begin{array}{c}\text { No of } \\
\text { Nodes }\end{array}$ & AODV & DSR & DSDV & IRPDSR \\
\hline 50 & 216500 & 334153 & 613065 & 1859360 \\
\hline 100 & 51008 & 51304.5 & 174442 & 3517280 \\
\hline 150 & 187842 & 171248 & 302579 & 3549440 \\
\hline 200 & 551278 & 479384 & 563308 & 2116480 \\
\hline 250 & 712032 & 736625 & 182306 & 1352160 \\
\hline 300 & 767654 & 897654 & 220914 & 4567680 \\
\hline
\end{tabular}

\subsubsection{PACKET DELIVERY RATIO}

In Figure 6.1.2 and table 6.1.2 we have observed that Modified DSR has a better PDR value up to 200 nodes when compared to DSR and DSDV having good PDR from 200 nodes. This is because in the time waited at a node, which findan path when broken any link then DSR is rendered useless at that point.Modified DSR slightly outperform than DSR.

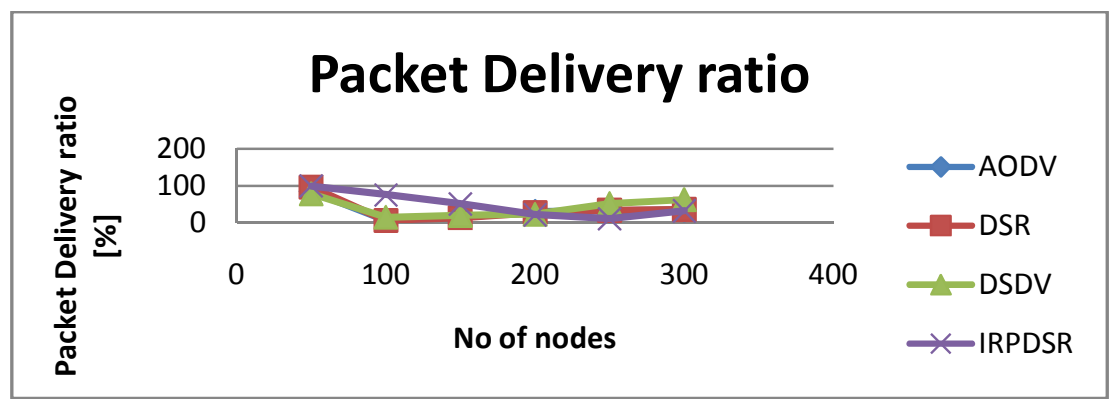

Fig: 6.1.2Packet Delivery Ratiovs Number of Nodes

Table 6.1.2Readings PDR vs No of nodes

\begin{tabular}{|c|c|c|c|c|}
\hline No of Nodes & AODV & DSR & DSDV & IRPDSR \\
\hline 50 & 84.8372 & 96.3248 & 78.4119 & 99.3248 \\
\hline 100 & 5.95087 & 6.16733 & 14.9198 & 75.53 \\
\hline 150 & 14.6446 & 13.7664 & 20.4225 & 51.2664 \\
\hline 200 & 30.9199 & 27.4362 & 23.0888 & 22.0276 \\
\hline 250 & 32.1339 & 33.6456 & 51.8034 & 11.3255 \\
\hline 300 & 34.654 & 35.7654 & 62.6581 & 32.6498 \\
\hline
\end{tabular}




\subsubsection{END TO END DELAY:}

Fig 6.1.3 shows the analysis of Delay. For DSR protocol it is found that average initial delay varies from 0.2 to 2.2. For AODV and DSDVobserved that the delay varies from 0.5 to 1 and continuously varying. Even the EX-DSR shows 0 to 2.0 which shows its inconsistency. Thus it can be seen that DSDV and AODV protocol performs better than other two in case of delay. The highest delay could be seen in case of Ex-DSR protocol.

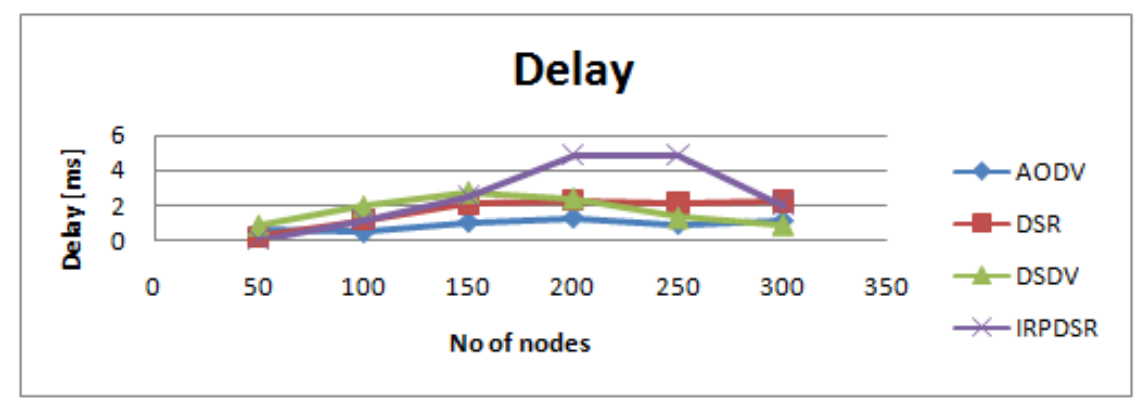

Fig: 6.1.3Delay vs Number of Nodes

Table 6.1.3 Readings Delay vs No of nodes

\begin{tabular}{|c|c|c|c|c|}
\hline No of Nodes & AODV & DSR & DSDV & IRPDSR \\
\hline 50 & 0.564031 & 0.243947 & 0.88559 & 0.0287013 \\
\hline 100 & 0.445553 & 1.19583 & 1.94105 & 1.14517 \\
\hline 150 & 1.05896 & 2.10176 & 2.72909 & 2.51869 \\
\hline 200 & 1.2968 & 2.27998 & 2.38812 & 4.84595 \\
\hline 250 & 0.92875 & 2.13679 & 1.31997 & 4.82215 \\
\hline 300 & 1.1275 & 2.26871 & 0.93151 & 2.0475 \\
\hline
\end{tabular}

\subsubsection{PACKeT DROPPING RATIO}

In the figure 6.1.4 observed that packet dropping ratio of IRP-DSR is lowest as compared to other all three protocols because of when the node size. When the node size increases then numbers of packet send source to destination and RREP request to destination s node due to characteristics of IRP-DSR form alternate path to send other packets which means smoothly delay applied to $2^{\text {nd }}$ last nodes send RREP request to source node.

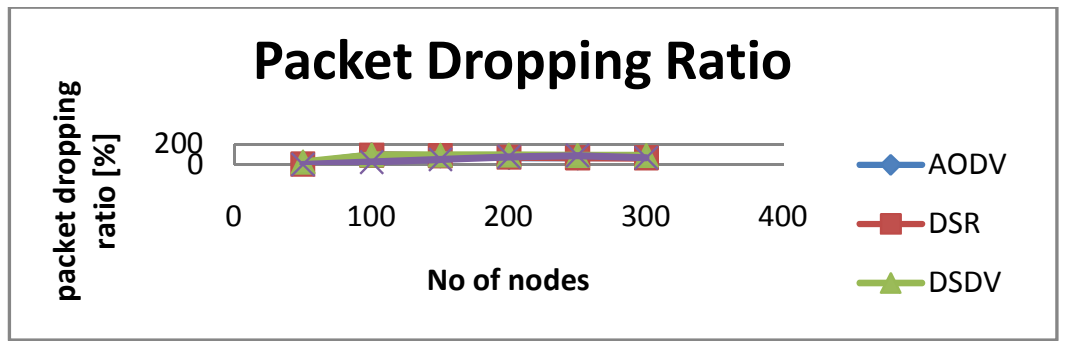

Fig: 6.1.4Packet Dropping Ratio vs Number of Nodes 
International Journal of Peer to Peer Networks (IJP2P) Vol.7, No.1/2/3/4, November 2016

Table 6.1.4 :Readings Packet Dropping Ratio vs No of nodes

\begin{tabular}{|c|c|c|c|c|}
\hline No of Nodes & AODV & DSR & DSDV & IRPDSR \\
\hline 50 & 15.1628 & 3.67521 & 27.0342 & 0.675214 \\
\hline 100 & 94.0491 & 93.8327 & 95.7602 & 24.47 \\
\hline 150 & 85.3554 & 86.2336 & 93.9476 & 48.7336 \\
\hline 200 & 69.0801 & 72.5638 & 94.38 & 77.9724 \\
\hline 250 & 67.8661 & 66.3544 & 91.4103 & 88.6745 \\
\hline 300 & 69.8948 & 65.5467 & 91.3248 & 67.3502 \\
\hline
\end{tabular}

\subsection{Graphs Of EX-DSR With Three Protocols In Non-Mobility Scenario}

In this section we are analysed the EX-DSR protocols in other three protocol in nonmobility scenario.

\subsubsection{THROUGHPUT}

In this figure 6.2.1 state that the M-DSR throughput is very high as compared with all three protocols because of If routes are ordered by freshness, and the first route fails, it is very likely old routes has stored in cache memory . By trying all the routes in the cache before sending a new route request, a lot of time and bandwidth is wasted. EX-DSR have a much larger and as per figure the maximum overload he packets which means the number of packets to be dropped is less. High throughput and less overhead when the network is congested and AODV, which keeps only one route per destination, performs well at low traffic.

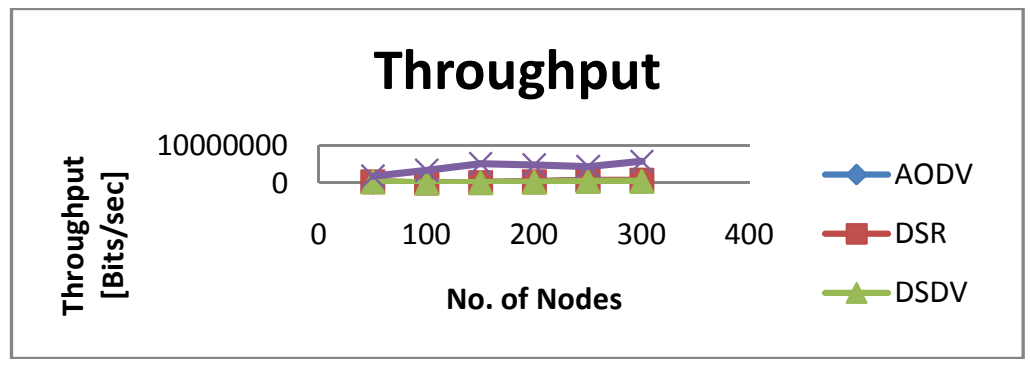

Fig: 6.2.1 Throughput vs Number of Nodes

Table 6.2.1: Readings Throughputvs No of nodes

\begin{tabular}{|c|c|c|c|c|}
\hline No. of Nodes & AODV & DSR & DSDV & IRPDSR \\
\hline 50 & 250113 & 327655 & 337387 & 1866400 \\
\hline 100 & 32258.3 & 31485.7 & 32288 & 3390080 \\
\hline 150 & 161367 & 169092 & 91200 & 5182880 \\
\hline 200 & 337186 & 338347 & 185418 & 4895680 \\
\hline 250 & 747659 & 745504 & 397731 & 4459680 \\
\hline 300 & 791234 & 795437 & 407641 & 5793760 \\
\hline
\end{tabular}

\subsubsection{PACKET DELIVERY RATIO}

Fig 6.2.2 shows that Modified DSR has a better PDR value when compared to DSR as simulation time increases but when the nodes are increases the M-DSR has decreases from average value of PDR 65. In this technique, only one route determined to be the main route and trend is to keep 
multiple routes and switch to a new one as soon as one fails. If the request times of two routes are the same, then a route with shorter hop count is given preference over a longer route.This is due to the reason that as node size has increase modified DSR find suitable alternate route to send the packet if the current link has broken whereas DSR has no choice at that point same are DSDV which become lower PDR then M-DSR.

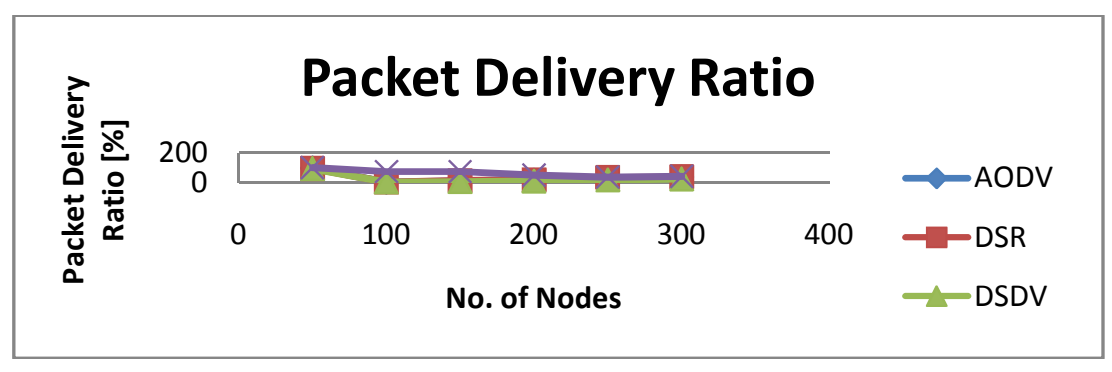

Fig: 6.2.2Packet Delivery Ratio vs Number of Nodes

Table 6.2.2 :Readings Packet Delivery Ratiovs No of nodes

\begin{tabular}{|c|c|c|c|c|}
\hline No. of Nodes & AODV & DSR & DSDV & IRPDSR \\
\hline 50 & 97.9535 & 94.453 & 93.7094 & 99.7009 \\
\hline 100 & 3.78286 & 3.78629 & 3.78629 & 72.7985 \\
\hline 150 & 12.5855 & 13.6763 & 7.12701 & 74.859 \\
\hline 200 & 18.9219 & 19.7196 & 10.4143 & 50.9525 \\
\hline 250 & 33.7407 & 34.8531 & 17.9539 & 37.3538 \\
\hline 300 & 37.5425 & 38.5334 & 25.6532 & 41.4138 \\
\hline
\end{tabular}

\subsubsection{END TO END DELAY}

In this figure observed that when the number of nodes is increases then the amount of delay also become increases in non-mobility scenario of M-DSR.The delay is also affected by high rate of CBR packets. The high delay at a mobility factor of 0-1 then the other protocols so that this MDSR protocol not satisfied the delay parameter.

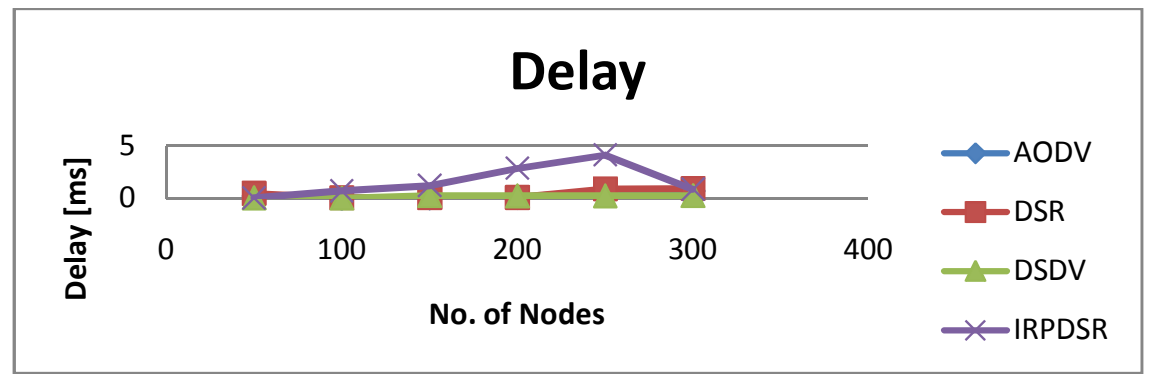

Fig: 6.2.3Delayvs Number of Nodes 
Table 6.2.3: Readings Delayvs No of Nodes

\begin{tabular}{|c|c|c|c|c|}
\hline No. of Nodes & AODV & DSR & DSDV & IRPDSR \\
\hline 50 & 0.208385 & 0.453372 & 0.0291946 & 0.0228194 \\
\hline 100 & 0.00346614 & 0.0286712 & 0.00235392 & 0.702086 \\
\hline 150 & 0.0397165 & 0.051656 & 0.237831 & 1.21257 \\
\hline 200 & 0.069358 & 0.0541943 & 0.222336 & 2.86172 \\
\hline 250 & 0.695796 & 0.885329 & 0.22659 & 4.14028 \\
\hline 300 & 0.70987 & 0.91234 & 0.23657 & 0.849929 \\
\hline
\end{tabular}

\subsubsection{PACKET DROPPING RATIO}

As shown in figure conclude that the AODV shows a better result than DSR. EX-DSR will have a much larger byte overhead than AODV at higher data rates. The M-DSR gives the better results of highest numbers of nodes then the other protocols. It is also possible that a route to destination might not have been discovered and the wait time that each node suffers might have produced that collision. At the highest data rate, DSDV is almost as good as DSR. both AODV and DSR are dropping a large fraction of the packets.

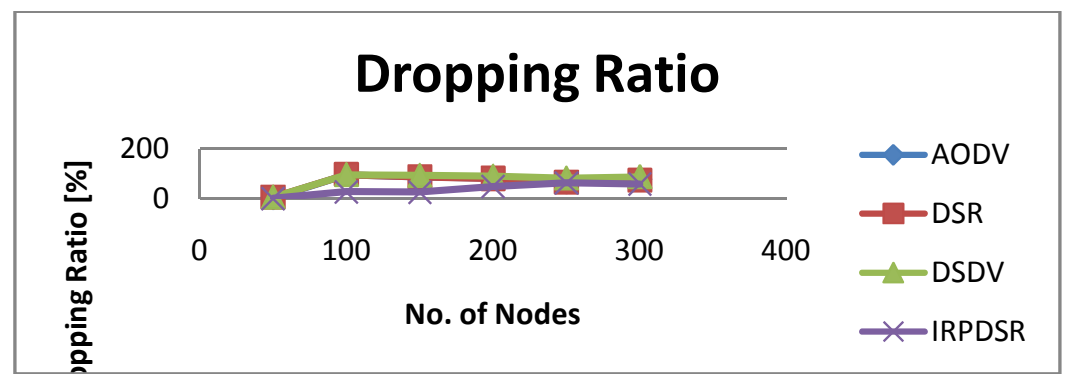

Fig: 6.2.6Packet Dropping Ratiovs Number of Nodes

Table 6.2.6: Readings Dropping Ratio vs No of Node

\begin{tabular}{|c|c|c|c|c|}
\hline No. of Nodes & AODV & DSR & DSDV & IRPDSR \\
\hline 50 & 2.04651 & 5.54701 & 6.2906 & 0.299145 \\
\hline 100 & 96.2171 & 96.2137 & 96.2137 & 27.2015 \\
\hline 150 & 87.4145 & 86.3237 & 92.873 & 25.141 \\
\hline 200 & 81.0781 & 80.2804 & 89.5857 & 49.0475 \\
\hline 250 & 66.2593 & 65.1469 & 82.0461 & 62.6462 \\
\hline 300 & 75.7678 & 72.5443 & 86.7656 & 58.5862 \\
\hline
\end{tabular}

\section{Conclusion And Future ScOpe}

This paper presents modified DSR protocol in Ad Hoc networks. To enhance the performance of DSR,MDSR has been introduced which using ACK path as the backup route and random delay on last node when the original route is no longer in use resolve the unnecessary data packets sends which means the retransmission happened when the any drop down packet then it should to resend. The intention of the mechanism is to reduce the waiting time of data transmission before route is re-established. In doing so, the packet dropping ratio will be reduced. Besides, the packet delivery ratio will been enhanced. The simulation results show that the new protocol has better 
performance than DSR and other protocols. Our proposed techniques perform significantly better than previously proposed modifications at high nodes in both scenarios.

Whenever the topology of the network changes, therefore, DSDV shows poor performance for dynamic networks and EX-DSR and DSR performs well in dynamic network as well as static network. However DSDV is more expensive due to take more time update the routing table in simulation time than EX-DSR at higher rates of mobility due to use the source routing as per AODV algorithm. Considering overall performance of EX-DSR it performs well in low (100) and high (200) nodes compared with other protocols.EX-DSR showed good performance at all mobility rates and movement speed. The EX-DSR protocol has not satisfied the some performance parameters like packet delivery ratio and delay due to highest numbers of nodes.

\section{REFERENCE}

[1] “An Analysis of DSR, DSDV, AODV and Adv.-AODV Routing Protocols inMANET" by Sandeep Gautam, Shashank dwivedi, IJRITCC, August 2015.

[2] "A Quantitative Analysis and Behavioral Study of Routing Protocols in MANET “ by Gyanendra Kumar Pallai, S Meenakshi, Amiya Kumar Rath, BansidharMajhi, IJCSMC, Vol. 3, November 2014.

[3] "Applications of MANET Routing Protocols in Sensor Network" by VenetisKanakaris, David Ndzi, and Kyriakos Ovaliadis, (IJRRAN), December 2011.

[4] "Assessment Of Throughput Performance Under NS2 In Mobile Ad Hoc Networks (MANETs)" by Liliana EncisoQuispe and Luis Mengual Galan, 2013 Fifth International Conference on Computational Intelligence, Communication Systems and Networks.

[5] "Comparison of MANET Routing Protocols in Different Traffic and Mobility Models " by Sabina Barakovi, SuadKasapovi and JasminaBarakovi, Telfor Journal,2011.

[6] "Enhancing DSR Protocol Performance in Mobile Ad Hoc Network Using ACK Reply" by ABDULLAH GANI, QI HAN, NOR BADRUL ANUAR, OMAR ZAKARIA,ISSN Feb 2009.

[7] "Enhanced-DSR: A New Approach to Improve Performance of DSR Algorithm" bySharmin Sultana, Salma Begum, Nazma Tara, ijcsit, April 2010.

[8] "Evaluation of AODV, DSR and DSDV Routing Protocols for Static WSNs: ASimulation Study" byAli A.S. Ihbeel, HaseinIssaSigiuk, Journal of Networking Technology, August 2012.

[9] NS-2 Network simulator http://www.isi.edu/nsnam/ns

[10] " Performance Evaluation of Energy Consumption in MANET" by Ashish Kumar, M. Q. Rafiq, Kamal Bansal March 2012

[11] "performance comparison of AODV,DSR and LAR1in Mobile Ad hoc network on simulation Time" by Rajeev Paulus, tanbeerkaur, reema Garg, journal,IOSR-JECE,Oct@ 2013.

[12] "Performance comparison of routing protocols in MANET by P.Manickam, t.gurubasker,IJWMN, journal, feb 2011.

[13] "PERFORMANCE INVESTIGATION OF ROUTING PROTOCOLS OF MOBILE AD-HOC NETWORKS USING CBR AND TCP TRAFFIC" by Samayveer Singh, A K Chauhan and AvinashSoam, JGRCS, June 2011

[14] "Performance Analysis and Comparison of MANET routing Protocols" by Kuljit Kaur, Swati Jindal, Lavneet Bansal, IJCSIT, 2011.

[15] "PERFORMANCE ANALYSIS OF AODV, DSDV AND DSR IN MANETS “ byAkshai Aggarwal, Savita Gandhi, NirbhayChaubey, IJDPS, November 2011.

[16] "Performance Comparison and Improvement of Routing Protocol-DSR" Nitin Tyagi : G.L.A.I.T.M, Mathura

[17] "PERFORMANCE COMPARISON OF MOBILE AD HOC NETWORK ROUTING PROTOCOLS “By Mandeep Kaur Gulati and Krishan Kumar, IJCNC, March 2014.

[18] "PERFORMANCE ANALYSIS OF AODV, DSR AND DSDV ROUTING PROTOCOLS IN MOBILE AD-HOC NETWORK (MANET)" by PARUL SHARMA, ARVIND KALIA AND JAWAHAR THAKUR, ISSN: 0976-8742, February 15, 2012

[19] "Performance comparison of AODV, DSDV, DSR routing protocols in MANET" by Preetigaharwar, Sunil gupta,research paper,IJARCSSE@2013. 
[20] "The effect of velocity of nodes on the performance of routing protocols in MANET" by ZubairIqbal,Prachigupta, ,journal,IJCA,july@2013.

[21] "Varying Pause Time Effect on AODV, DSR and DSDV Performance " by Zafar Mahmood, Muhammad Awais Nawaz, DrMudassar Iqbal, Saleem Khan, Zia ulHaq, ijwmt, March 2015.

[22] "Competitive study of Ad hoc Routing protocol AODV,DSR,DSDV in Mobile Adhoc network" by Pranav kumarsingh, Dipankar Sutradhar, Journal ISSN.

\section{AuTHORS}

Paresh Acharekar is working as Software consultant in Atos Origin India Private Limited (French MNC), India and I am student of VIT, Engineering College Mumbai, India. My research is focus on routing protocols in MANET Mobility as well as NonMobility scenarios and Wireless networking, Ad-hoc networks, Network management.

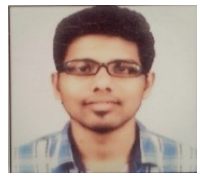

Dr. Saurabh Mehta is Professor and Head Department of EXTC, VIT Engineering College Mumbai, India and his area of specializations includes a core wireless network, Sensor Network. His wireless and NS2 ideas helps me lot in this research paper.

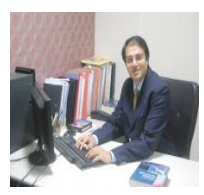

Prof. Shraddha Panbude is working in VIT Engineering College Mumbai, India and she is my guide of Master's project.

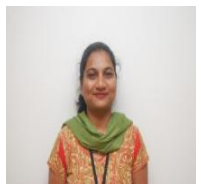

